Please refer to the definitive version of this article when citing:

Mikkelsen, M.V. \& Cohen, S.A. (2015). Freedom in mundane mobilities: Caravanning in Denmark. Tourism Geographies, DOI: 10.1080/14616688.2015.1084528.

\title{
FREEDOM IN MUNDANE MOBILITIES: CARAVANNING IN DENMARK
}

\begin{abstract}
Freedom is a widely discussed and highly elusive concept, and has long been represented in exoticised, masculinised and individualised discourses. Freedom is often exemplified through the image of a solitary male explorer leaving the female space of home and familiarity and going to remote places of the world. Through in-situ interviews with families caravanning in Denmark, the primary aim of this study is to challenge existing dominant discourses surrounding the subject of freedom within leisure and tourism studies. Secondly, we shed further light on an under-researched medium of mobility, that of domestic caravanning. This serves to not only disrupt representations of freedom as occurring through exoticised, masculinised and individualised practices, but to give attention to the domestic, banal contexts where the everyday and tourism intersect, which are often overlooked. This novel repositioning opens up new avenues in tourism studies for critical research into the geographies of freedom in mundane, everyday contexts.
\end{abstract}

Keywords: freedom, domestic caravanning, family holidays, gender, everyday, Denmark

\section{Introduction}

Freedom is an elusive construct that has long been a subject of scholarly interest and discussion (Berlin, 1969; Hirschmann, 2002). The treatment of freedom spans widely from that of movement or speech, to political and religious freedom, to name but a few. Moreover, tourism and notions of freedom are inextricably linked together. 'Freedom to move' is a trope in popular and academic discourse, frequently used in tourism texts to 'promulgate a romanticised view of the vacation as a key vehicle for personal liberation and license' (Caruana and Crane, 2011: 1495-1496). Mobility rights are, however, highly uneven as the mobility of some often render others immobile (Priya and 
Cresswell, 2008; Skeggs, 2004; Adey, 2006). Idioms such as 'getting away from it all', 'don't be a slave to the grind', 'get off the beaten track' often imply dominant discourses on freedom, found in movies and books like Into the Wild (1996; 2007), which portray exoticised, masculinised and individualised representations of freedom. Automobility has also been a recurring symbol of freedom, with Thelma and Louise (1991) and Kerouac's (1957) On the Road epitomizing the car's association with autonomy and independence (Ganser, 2009; Cresswell, 1993). Within leisure and tourism studies, freedom is often represented through extraordinary acts of adventuring to remote locations (Kane and Tucker, 2004), typically alone and often taking a masculinised point of view (Franklin and Crang, 2001; Hannam, Butler and Paris, 2014).

Caravanning is a relatively neglected area of study, and the concept of freedom has not been studied in-depth in this context. Caravanning is defined here as a leisurely activity of dwelling temporarily in mobile units such as camper trailers, pop-tops, caravans, tents or recreational vehicles (henceforth referred to as dwelling units). Tents and cottages do not typically belong under the 'caravan' definition but as integral elements of the caravan site-mix they too are included in this term. Furthermore, the sparse literature on caravanning has mainly given focus to people travelling for months on end, leaving their home and living full-time in RVs, or migrating for entire seasons (e.g. Mahadevan, 2013; Onyx and Leonard, 2005; Mings, 1997; Viallon, 2012; White and White, 2004). The academic gaze in caravanning has thus paralleled hegemonic representations of freedom more widely, by exploring relatively extreme contexts. This is not surprising, however, given the tendency in tourism research to prioritise the study of international tourists (Cohen and Cohen, 2015) and the extraordinary, often at the expense of studying domestic (Ghimire, 2001) or more everyday and mundane mobilities (Franklin and Crang, 2001; Larsen, 2008; Edensor, 2007; Binnie et al., 2007).

In this paper, our aim is to challenge dominant ideologies of freedom as exoticised, masculinised and individualised. The term 'exoticised' is defined here as having portrayed something as extraordinary or unusual, 'masculinised' refers to having been made to have male qualities or masculine characteristics, and 'individualised' is understood as having been portrayed through the individual. We carry out this aim by examining performances of freedom within everyday sociality, through an empirical account of domestic caravanning in Denmark. The focus of this study's inquiry into performances of freedom is therefore closer to 'home' (sometimes 3 to 6 miles from where people live), and through exploring practices seemingly quite similar to those in the everyday. Furthermore, domestic caravanning in Denmark is often undertaken in the close companionship of one's family members, friends and other caravanners, as opposed to an individualistic mode. The experiences 
people have with these mundane spaces are vital in constituting mobile behaviours (Doughty and Murray, 2014), or as Featherstone (1992: 160) suggests; 'everyday life is the life-world which provides the ultimate ground from which springs all our conceptualizations, definitions and narratives'. As such, the objectives of this paper are two-fold; firstly, our primary objective is, through in-situ interviews with families caravanning in Denmark, to challenge existing dominant discourses surrounding the subject of freedom within leisure and tourism, in order to disrupt representations of freedom as occurring through exoticised, masculinised and individualised practices. The second objective is to shed further light on an under-researched medium of mobility, that of domestic caravanning. We do so through a theoretical approach that prioritises the everyday, gender issues and the perspective of families, as a basis for empirically unpacking the meanings given to freedom, as well as the ways freedom is practiced, in this relatively neglected context.

\section{The Exoticisation of Freedom}

Ideologies of freedom have historically been represented through geographical movement and conquest, wherein the heroic quest for freedom was sought in remote locations of the world (Sutherland, 2014; Skeggs, 2004). In the Western world, freedom is often portrayed through mobility, via ideals of people moving faster, further and more frequently (Jensen, 2006). Against earlier more sedentary views of societies, we now talk of the death of distance in a globalised world increasingly defined by hypermobility and restlessness (Sutherland, 2014). As Beck and Beck-Gernsheim (2001: 25) argue:

In the global age, one's own life is no longer sedentary or tied to a particular place. It is a travelling life, both literally and metaphorically, a nomadic life, a life spent in cars, aeroplanes and trains, on the telephone or the internet, supported by the mass media, a transnational life stretching across frontiers.

Such a discourse is problematic, however, as these adventurous, nomadic movements can mainly be accessed by only those who are well-resourced, i.e. the elite (Adey, 2006; Urry and Larsen, 2012). The nomad has become a metaphor for mobility 'countering the monotony of everyday life routines that many Westerners have apparently become weary of" (Ganser, 2009: 176). Nomadic theory has resultantly been criticised for its take on freedom as romanticised and exoticised (Sheller, 2014; Ganser, 2009). 
Embedded within these ideologies, freedom within tourism and leisure studies is often enacted through discourses of 'extreme' encounters, opposing the banal and the everyday. Freedom within these fields of study has been portrayed through counter-spaces of liminality, demarcated from everyday life and mundanity (Rojek, 1995), which promise escape from the rules and regulations and daily routines of the everyday: spaces where you can dress, eat, sleep and act differently (Franklin 2003; Shields 1991). Recent studies highlight freedom in extraordinary acts of adventure such as mountain-climbing (Beedie and Hudson, 2003), or kayaking (Kane and Tucker, 2004). The association of freedom with a far-away-travelling, solitary subject, seeking out extraordinary experiences, has thus been a common representation. However, as Jensen (2009: 145) stresses, 'there is a need to recognise that the impacts of mobility to our understanding of place, identity and subjectivity have just as much to do with our mundane everyday life experiences as with the exotic and heroic traveller's tales that makes up the cultural stereotypes of the meaning of mobility.' Similarly, Obrador, Crang and Travlou (2009:5) argue that the 'significance of the banal in tourism has been systematically overlooked by dominant perspectives which have privileged the exotic and the spectacular'. There is consequently a need to illuminate the concept of freedom within everyday, banal, mundane settings.

Calling into question the rootlessness and restlessness of nomadic theory, travelling is not just about escaping home, but it can be just as much about creating a home away from home (Larsen, Urry and Axhausen, 2007). Rather than seeking out unfamiliar spaces, some wish to create a safe, familiar tapestry on holiday. This sense of ontological security and familiarity is important to experiences of place, and perceptions of freedom may be closely linked to the space itself. As Sheller (2008) argues, a kind of freedom of mobility is inherent in the space itself, or at least in the way it is spatially practiced. Places acquire their connotations through social performances and are thus not fixed but fluid (Coleman and Crang 2002; Baerenholdt et al 2004). Accordingly, we should not forget the everyday as "we struggle to ground the large and abstract concepts of contemporary sociological analysis in the ordinary life of social beings: where it all takes place' (Jensen, 2006: 66). Further to the exoticisation of discourses of freedom, all too often the subject undertaking such far-way journeys is represented as male. 


\section{Freedom as Gendered}

Philosophical discussions and definitions of basic freedoms have been criticised for largely taking a masculine standpoint, where the subject from which freedom is defined and discussed is male (Wearing, 1998; Hirschmann, 2002). Mobility studies have likewise traditionally been marked by a distinct genderedness, built on various divisions wherein the most noted is the one of public/private, reflecting related dualisms of masculine/feminine, mind/body, global/local and movement/fixity (Priya and Cresswell, 2008; Casinowsky, 2013; Enevold, 2000). Analysing women's road narratives, Ganser (2009: 86) supports this by arguing that '[t]he dream of and quest for freedom has always been cast in a romantic vein tightly linked to dominant ideas of masculinity.'

Through the history of Western philosophy, gender segregation became most visible in the division of public and private space: women occupied private, domestic spaces, traditionally associated with the embodied, the natural and the family, while public and global spaces were in contrast occupied by men (Morley, 2000). These latter masculine spaces symbolised disembodiment, the mind and rationality, where knowledge was created (Alcoff, 1996). The female, domestic realms were in opposition seen by men as spaces of 'bodily distractions' and 'emotional disturbances' (Alcoff, 1996: 16). Mobility has been likewise troped in gendered terms: the masculine was historically associated with nomadic movement, conquest and adventure, while the feminine was associated with stillness and fixity (Priya and Cresswell, 2008; Morley, 2000; Massey, 1994). These distinctions are also reflected within geographical research where fieldwork has been cast as a tough and heroic activity, and a masculine endeavour (Rose, 1993; McDowell, 1993), while the field itself has been represented as a space of the feminine and seductive, 'a wild place that must be observed, penetrated and mastered by the geographer' (Sparke, 1996: 212).

Gendered ideologies of freedom in mobility spill over into the fields of travel, tourism and leisure. Work-related travel has traditionally been a male domain (Casinowsky, 2013), and freedom is inscribed into discourses of 'frontier travel', where the male would seek freedom through adventuring to remote locations of the world (Tazim and Robinson, 2009; Jokinen and Veijola, 1997). A historical example is the English Grand Tour, which was undertaken by young males only, as part of their education (Klooster et al., 2008). As Priya and Cresswell (2008) contend, elements of the masculinity of the 'Grand Tour' are still found in tourist mobilities in the modern Western world. Masculinity still predominates adventure mythology (Kane, 2013; Kidder, 2013). For example, Ong and du Cros (2012: 750) study discursive spaces of online Chinese backpacking forums, noting that these 
backpacker communities are highly gendered: "male and female backpackers were expected to fulfil their gender roles: men to be assertive, adventurous and rugged and women to be submissive, domestic and gentle." Furthermore, Parmett (2015) argues that snowboarding culture is constituted as masculine.

Some studies have problematised the privileging of men's access to freedom of movement, by mobilising feminist critiques of nomadic theory (Sheller, 2014). For example, Elsrud (2001) interviewed both female and male long-term budget travellers, in order to redress a gender bias in research on backpackers. More recent studies focus on women participating in traditionally maledominated spheres of adventure recreation and wilderness (e.g. Little, 2002; Boniface, 2006; McNiel, Harris and Fondren, 2012). For example, Dilley and Scraton (2010) examined women's rock climbing from the perspective of serious leisure. But research on the voices of men is still lacking in some contexts, such as in the case of fathers in family tourism (Buswell et al., 2012; Schänzel and Smith, 2011). There is a lack of research on family holiday experiences inclusive of both femininities and masculinities.

In summary, engaging in adventure on holiday is typically associated with physical and intellectual challenge and is traditionally perceived as male-dominated (Little, 2002; Capdevila, 2003). The masculinisation of freedom through adventure lies in the male 'ruggedness' of overcoming challenging obstacles in order to be 'free'. An important part of this 'trial' is in solitariness, in that the male achieves freedom on his own.

\section{The Individualisation of Freedom}

Beck and Beck-Gernsheim (2001: 22) argue that 'individualism is written into western culture', with individual self-fulfilment and achievement at the forefront. Individualisation is tied to the idea of freedom from social constraint (Savage, 2000), wherein life decisions previously made by community are increasingly made by individuals (Beck, 1992). Discourses of choice are central to the Western production of ideas of individuality, where contemporary consumerist discourses are saturated with the ideals self-actualization and self-transformation (Skeggs, 2004). Following Cronin (2000) we are in a historical period of 'compulsory individuality', where discourses lead us to believe individuals are increasingly defined by 'free choice', despite power asymmetries in doing so. A consequence of 
this is that discourses of freedom are not only masculinised and exoticised, but also centre on freedom of, and through, the individual.

The car has been a primary symbol of freedom and independence for the individual (e.g. Flamm and Kaufmann, 2006; Doughty and Murray, 2014; Sheller and Urry 2000; Freudendal-Pedersen, 2009), providing in theory freedom to go wherever one wants, whenever one wants (Hagman, 2003; Jensen, 1999). The notion of individualised automobility is closely connected to characterisations of contemporary Western societies as hyperautomobile (Freund and Martin, 2007), where daily transport becomes highly individualised and people travel further and more frequently. Hyperautomobility has led to 'a fragmentation of a sense of neighbourhood community, with consequent social problems' (Vannini, 2009:6). Thus, freedom in the form of the private car has not only been blamed for the erosion of public spaces (Habermas, 1992), but also the erosion, or fragmentation, of communities. As such, the car itself has been a driver of individualisation in late modernity.

Within tourism studies, discourses of freedom have been represented in a similar manner as experienced by the lone subject (Obrador, 2012). For example, Caruana and Crane (2011: 1504) analysed constructions of freedom by cultural brokers and two of the themes they found were young, single hedonistic pleasure seekers, and independent tourists seeking to get 'off the beaten track'; both of these illustrations focus on individuals. Likewise, Mehmetoglu, Dann and Larsen (2001) studied solo travellers in the Norwegian Lofoten Islands, finding they sought freedom through adventure and escaping home and other people. More generally, ideologies of freedom in tourism have often taken an individualised viewpoint, as freedom is typically sought away from other people and away from other tourists (Dann, 1999).

To contrast such individualised perspectives, there remains a need in tourism research to focus on 'thick sociality'; tourism studies have largely ignored sociality and 'thereby overlooked how much tourist travel is concerned with (re)producing social relations' (Larsen, 2008: 25). Mobility is not just about the individual, as much of the literature leads us to believe, but is about individuals interacting with family, friends, community and society more widely (Hanson, 2010). Even though families make up a large part of the tourism market, the study of families still requires a more holistic approach in tourism research (Schänzel, 2010; Carr, 2006). A further shift in focus is needed from individuals to the social dynamics of family holidays, with caravanning representing one popular family holiday mode. 


\section{Freedom in Domestic Caravanning?}

Everydayness, banality and the mundane are part of most tourist spaces (Larsen, 2008; Edensor, 2007), and this is particularly the case for Danish caravan sites. Despite its long history, and status as an important component of tourism for several countries (e.g. Australia, United Kingdom, Denmark), little research has been done on domestic caravanning. Tourism research has instead historically gravitated towards more extraordinary, international contexts (Cohen and Cohen 2015; Ghimire, 2001).

A subset of drive tourism (Caldicott, 2011; Blichfeldt and Mikkelsen, 2014), caravanning in Denmark spread with the increase of the privately owned car, and quickly became a popular holiday choice (Den Jyske Historiker, 2012). Some of the main features of caravanning is its sociability (Blichfeldt and Mikkelsen, 2013; Triantafillidou and Siomkos, 2013), where interacting with fellow caravanners is an important part of the overall experience. Another central theme of caravanning are experiences of deep connection with nature (Jacobsen, 2004; Kyle et al., 2006; Garst, Williams and Roggenbuck, 2009) and an appreciation of the trip being unplanned and not having fixed schedules (Viallon, 2012). Similar themes have been identified in studies of second home tourism (e.g. Hall and Müller, 2004; Jaakson, 1986; Williams and Kaltenborn, 1999).

Caravanning is difficult to define and delimit as it takes on a range of different meanings depending on context. However for this study, caravanning is defined as it was experienced at the caravan sites, as people travelling in camper trailers, pop-tops, caravans, tents or RV's. Caravanning often comprises engaging in practices somewhat resembling those at home, like grocery shopping, cooking and dishwashing (White and White, 2007; Viallon, 2012), and generally spending a great deal of time doing everyday, mundane things. Caravan sites in Denmark, usually scattered along coastlines and close to cities, span from more spartan sites with electricity and running water to elaborate sites with on-site restaurants, cafes and individual bathrooms.

Experiences of freedom in caravanning, although fleetingly mentioned as a motivational theme in a number of studies, (e.g. Viallon, 2012; Counts and Counts, 2004; Hardy, Gretzel and Hanson, 2013), have not been analysed in depth. When touched upon, this has been mainly in the context of longterm caravanning: for example, White and White (2004: 212) studied people travelling for more than three months in RV's in the Australian outback and found that they sought 'freedom from pressures 
and constraints' and freedom to move on if they wanted. Similarly, Onyx and Leonard (2005) compared caravanning 'snowbirds' (seasonal migrants who winter in warmer climates [Mings and McHugh, 1995]) with 'grey nomads' (people aged over 50 years, caravanning independently for an extended period within their own country), and found that both groups were motivated to experience adventure and freedom. In summary, there are few analyses of freedom within caravanning, and these have tended to explore relatively extreme modes of caravanning. In this study, we instead aim to extend the study of freedom in caravanning to a more everyday and domestic context, that of domestic caravanning in Denmark.

\section{Methodology}

This paper is part of a wider project examining families' holiday experiences at Danish caravan sites. Our focus here extends from recent interest in tourism research in the everyday, the mundane and the banal, in contrast to a historical emphasis on exoticised tourism practices (Harrison, 2000; Seigworth and Gardiner, 2004; Holloway and Holloway, 2011; Larsen, 2008; Haldrup, 2004; Binnie et al., 2007; Edensor, 2007). The empirical material for this paper is based on 82 interviews with 166 interviewees, all of which were domestic tourists (i.e. Danish), as well as a short period of participant observation. Our philosophical position as researchers is within the critical interpretive research paradigm, adopting a relativist ontology and a subjectivist epistemology (Denzin and Lincoln, 2005; Jordan and Gibson, 2004).

The majority of the interviews were carried out in the peak caravanning season (June - August) in the summer of 2013 and 2014. In these periods, the lead author visited five caravan sites scattered around Denmark (Figure 1): Hirtshals Camping, Aalborg Family Camping, Skiveren Camping, Lakolk Beach Camping and Hasmark Beach Camping. The spots marked with an ' $\mathrm{x}$ ' are where a longer time was spend observing, as will be explained below. People were typically approached while they were sitting in front of their dwelling unit relaxing, reading or eating, or in the common kitchens. 

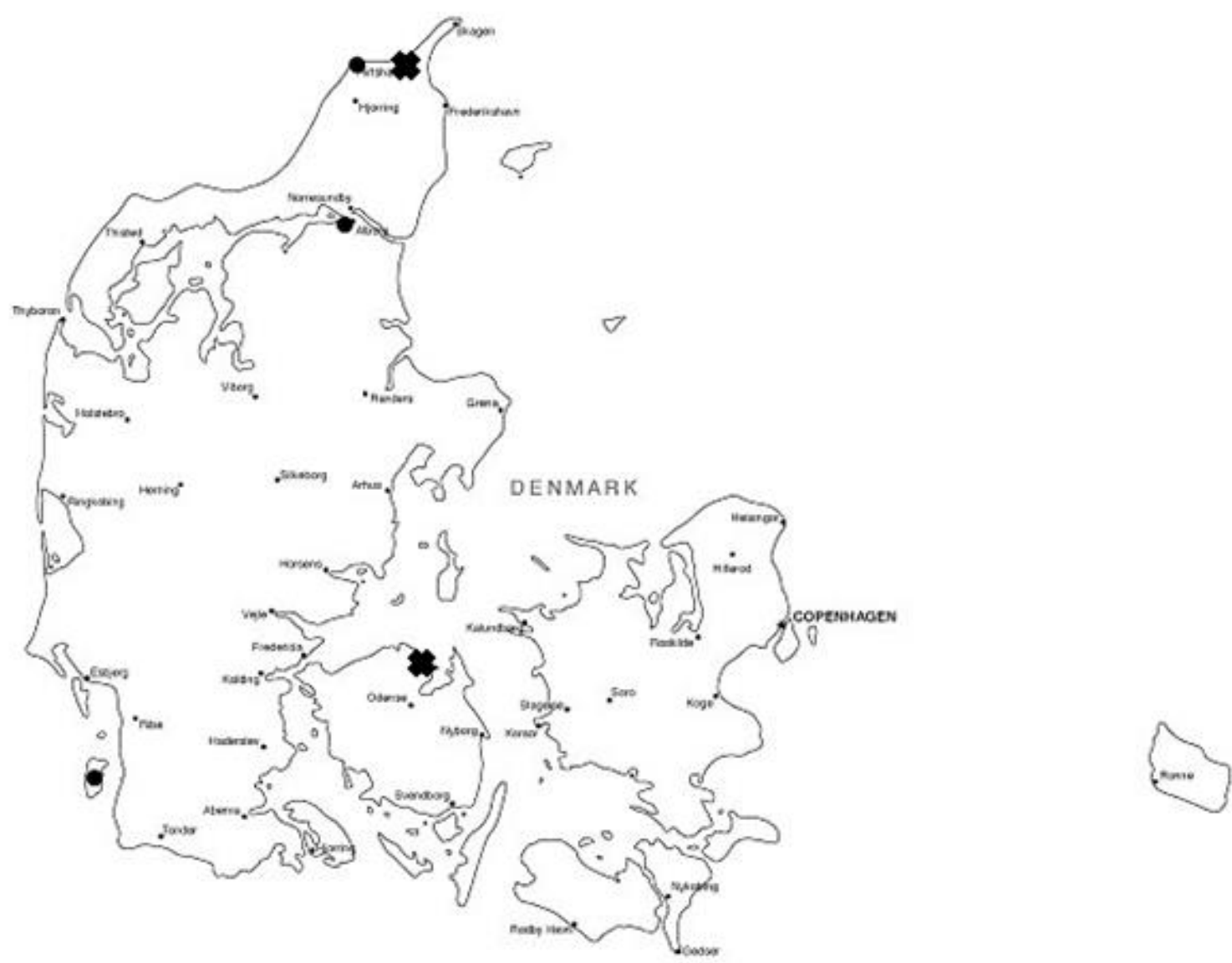

\section{Figure 1 Map of field locations}

There are around 500 caravan sites in Denmark, most placed along the coastline and close to cities (www.visitdenmark.dk). Danes going caravanning in Denmark peaked in 2008 with 9 million nights and has since been declining to 8.2 million nights in 2014 (www.danmarksstatistik.dk). Due to the limited literature on domestic caravanning there were few a priori themes to structure the interview guide. The initial phases of interviewing were therefore based on conversational, explorative interviews, focused on a broader spectrum of themes such as 'why caravanning', 'activities on and off the site' and 'being social'. Later phases focused on identifying and further exploring key themes. The theme of 'freedom' was not part of the initial interview guide, however, it quickly became evident that this concept was key in peoples' reflections on their caravan holiday. In line with the critical interpretive research paradigm, we encouraged open conversation and that participants speak about 
their experiences on their own terms. Correspondingly, research is collaborative, in the sense that the researcher and the researched work together in the production of knowledge (Schwandt 1998; Meunier, 2013). Due to the emergence of freedom as a central theme, and in line with the iterative nature of the interview process, further elaborations on freedom in summer 2014 were intentionally teased out.

The average length of the interviews were 30 minutes, however some of the interviews lasted close to two hours, while others were cut short (e.g. 15 minutes) as people needed to 'go somewhere' (or merely wanted to carry on 'doing nothing', see Blichfeldt and Mikkelsen, 2013). Primarily nuclear families were interviewed, with one to three younger children, as these made up the majority of the guests. It is noteworthy here, that the lead author did not meet any families on holiday from an ethnic minority, and only one same-sex couple. Multiple family members were interviewed where possible, as it was our intention to go beyond a focus on the 'solitary subject', and instead access relational experiences of freedom (Manderscheid, 2014; Small, 2008). However, during the interviews the children were often away 'doing their own thing' (Mikkelsen and Blichfeldt, 2013), and the voices of adults dominate the data. Effort was made to stratify the sample across ages and a relatively equal gender distribution; this primarily meant reaching men (71), women (95), 'empty nesters' (79), families (68) and younger people aged 25-35 (19).

In order to go beyond peoples' stories and interpretations of caravanning, the interviews were supplemented with observations (O'Reilly, 2005; Conquergood, 2002), by staying one week at Hasmark caravan site in the southwest and another week in north Jutland at Skiveren caravan site. The lead author is a Danish woman in her late 20s with barely any experience in caravanning. This allowed for a fresh perspective on otherwise potentially taken-for-granted performances of caravanning. The lead author engaged in some of the same practices as the other guests, who routinely practiced regular, grounded routines such as cleaning, cooking and dishwashing, which constituted patterns and rhythmic ways of dwelling that are 'habitually, unreflexively performed' (Edensor and Holloway 2008: 487). Interviewees found it difficult to give words to these embodied and habitualised practices. As these made up a large part of caravanning 'doings', and are central to how we become tourists (Obrador, 2003), the observations naturally fell on these practices. This resulted in co-performative participant observation (Conquergood, 2002), often undertaken in the common kitchen (see Figure 2). 


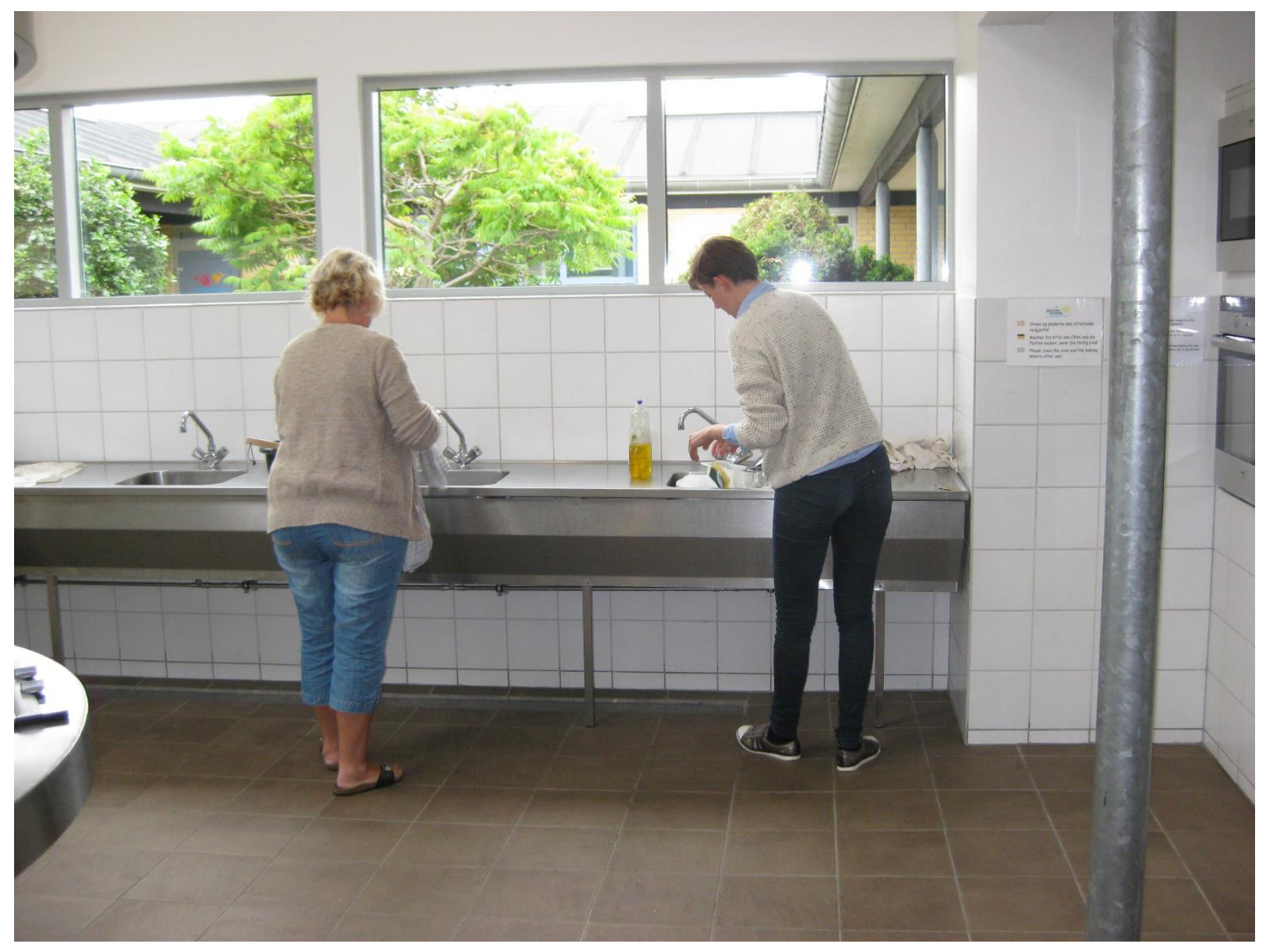

Figure 2 Common Kitchen

The common kitchens are frequently used by guests throughout the day for washing dishes, cooking and socialising with others. The lead author would do dishes and cook while engaging in small talk with fellow caravanners. As such, the practices or 'task-scapes' (Ingold, 1993) caravanners engage in were explored first-hand. These talks that accompanied participant observation were sometimes recorded and sometimes not, with notes on non-recorded talks written up during intermittent breaks. All interviewees, including those spoken with in the common kitchens, gave consent to be included in the study. The authors did not seek consent from those individuals who were casually observed in terms of their daily rhythms, but were not included in the interview work.

The data was analysed using thematic analysis (see Boyatzis, 1998; Braun and Clarke, 2006). This approach allowed for identifying patterns and facilitating interpretation of the data. The digitally recorded interviews were transcribed verbatim, and the notes from the non-recorded interviews and the transcripts were read and re-read to further familiarise the lead author with the content; emergent 
themes and subthemes were subsequently identified (Boyatzis, 1998). In this process, sentences that were affiliated with the same theme were clustered together. For example, within the overarching theme 'freedom' subthemes were 'sociability', 'mundanity' and 'de-gendering'. Furthermore, the thematic analysis went beyond organising and describing to interpreting, by theorising the patterns and their broader meanings beyond a surface level (Braun and Clarke, 2006). This comprised relating the themes back to the research focus and the literature. Other motivational themes, such as seeking and escaping (see Iso-Ahola, 1982) were identified, but freedom emerged as the dominant theme and is thus the focus of this paper. The trustworthiness of the data was checked through theoretical triangulation, by drawing on theoretical perspectives across geography and sociology (Decrop, 1999). Furthermore, data triangulation was achieved using a variety of data sources (Decrop, 1999; Thurmond, 2001), both explorative and in-depth interviews and participant observation. We recognise that these findings only reflect the participants in this study and cannot be considered representative.

\section{Performances of Freedom}

Interviewees often turned to the theme of freedom in explaining what caravanning 'is all about'. This was particularly the case towards the end of interviews, when asked to sum up caravanning in a few words. Put bluntly by one woman in her forties, who was travelling with her husband and their two daughters, 11 and 17: 'If you love freedom, you love caravanning.' For her and a majority of the interviewees, a major contributor to their love of the caravan holiday is the feeling of freedom. People's narratives on freedom manifested themselves in a variety of different meanings and practices, however, here they are analysed in terms of the following themes that emerged: social freedom, mundane freedom and de-gendering freedom.

\section{Social Freedom}

'Being free' has often been associated with independence and individualisation (Sager, 2006; Doughty and Murray, 2014). This has furthermore been strongly coupled with the car and 'freedom of the road'. Ideologies of freedom often rest on the conception that freedom is achieved by escaping the social spaces of other people. In the present study, however, the majority of caravan guests 
expressed their experiences of freedom as arising through socialising with other people. Being connected to other people was expressed as an important part of the sense of freedom. This connection to other caravanners is highlighted by a female caravanner (mid-forties, travelling with her husband) living just an hour away from the caravan site on Rømø Island:

The great thing about caravanning is freedom. In a holiday home for example, you don't have any contact with your neighbours. At a caravan site like this, we know all our neighbours and we meet every now and again.

She emphasises the sociality of the caravan site and how she experiences freedom in close proximity to other people, contrasting this with a holiday home where socialisation mostly occurs only with those one is staying with, typically family (Larsen, 2012). Part of experiencing freedom here is having contact with your 'neighbours'; this is how people would typically refer to nearby caravanners. Not only are nearby dwellers considered as neighbours, but the path their dwelling plot is placed on is referred to as 'their street'.

Another participant, a man in his mid-seventies travelling with his wife, when asked what he likes about a caravan holiday, also underlined freedom in socialising with others:

It's the atmosphere at a caravan site, it's the freedom. We like to talk to people when they pass by on the street and we know everyone on this street. We've been coming here for many years so everybody knows everybody and that's just so cosy.

Like many of the guests at this site and others, this participant had been returning to the site annually for many years. Interviews were held with people who had been coming to the same site for 15, 20 and 40 years. The freedom that participants perceived through socialising with others, rather than 'escaping', reflected a mutually reinforcing relationship, wherein it takes freedom to be social and it takes sociability to experience freedom.

The physical layout of the caravan site is crucial in rendering opportunities to 'talk to people when they pass by on the street'. Sites consist of several public and semi-public spaces: guests have their own private dwelling unit, for example a caravan, an RV or a tent, and a small semi-private area right in front that immediately spills into public areas of the 'street' and the site in general. People spend a great amount of their time outside of their dwelling unit, particularly when consuming meals, reading and relaxing. As such, socialising with others is almost unavoidable and the blurred lines between 
public and private are easily penetrated. These findings were underpinned by participant observation as the sociality people spoke of also showed through in the performing of caravanning, i.e. the 'good mornings' and 'hellos' and general openness towards sociality. Experiencing freedom through socialising consequently lies not only in being familiar with other people, but also in being familiar with the environment of the site. As many of the guests are repeat visitors they know the respective site, its facilities and the performative competences (Edensor, 2000; Vannini, 2011) of being a caravanner. This mode of 'being-in-the-world' (Obrador-Pons, 2003) is a way of being familiar with both the space and the people, which enable a feeling of safety.

Some interviewees socialised much more with their neighbours at the caravan site than with their neighbours at home. Rather than being an expression of social distance from neighbours at home, this seemed driven by the change of social environment when on holiday (though some are not physically far from home). As Löfgren (1999) argues, this transformation lies not so much in actual geographical movement, but in a different social space of 'elsewhereness'. As such, the sociality that goes on at the caravan site is enabled by this space being experienced as different from that at home. One man in his mid-sixties, caravanning with his wife, observed:

We have our next-door neighbours from home as neighbours here, we often have a chat and we have dinner arrangements occasionally, back home we don't really socialise at all.

This participant illustrates how the ecology of the caravan site facilitates socialising with his neighbour, even though this is the same neighbour he has at home, with whom he rarely socialises with. As Veijola and Falin (2014: 14) argue, mobile dwellings 'allow people more personal freedom in how they perform their neighbouring than permanent neighbourhoods do.' In this case, the caravan site allows for casual chats and social interaction more so than the private spaces they may experience in their home neighbourhood (see also Collins and Kearns, 2010). However, this does not mean that caravanners wish to be with other people all the time; rather, a 'good holiday' included spending time close to others, reflecting a non-obligated, casual sociality. 


\section{Mundane Freedom}

Freedom was also coupled with the practice of mundane, everyday activities. Most guests would begin their morning with breakfast in front of their dwelling unit, followed by activities such as reading books, going for a run or a walk, doing dishes, grocery shopping or leaving the site to visit nearby attractions, for example churches or the closest town. A great deal of activity was concentrated in the common kitchen throughout the day. In the morning people would do dishes before breakfast, at lunchtime food would be prepared and sometime in the afternoon further dishwashers would come in before dinner. The most time in the kitchen was spent at dinner cooking and socialising. A woman in her mid-fifties travelling with her husband and their two dogs paints a picture of her and her husband's activities:

We relax, I brought my knitting and we read books. He does crosswords... we talk and play cards and get closer to each other in a different way than if we were at home. We barbeque and relax in the evening, there are no obligations.

Her holiday, strongly associated with perceptions of freedom, is saturated with non-spectacular, mundane doings. This was typical within many of the participants' narratives on what they do when caravanning. Freedom is represented through de-exoticised, banal activities. Furthermore, these doings were routinely expressed in a positive, transformative light. These everyday, banal activities are experienced not as that, but as unique, transformative moments. One woman in her mid-forties travelling with her husband and two adolescent children, illustrated this with the example of doing dishes:

We were actually just talking, when we were doing the dishes, the eldest and I, about how it is something completely different (than at home). We get to talk like we don't do at home. Even though we don't do the dishes by hand at home, we do that here. At home it's just chores, here we do it because it is so cosy, because you don't have something you have to do afterwards. You don't have the time aspect, I've taken off my watch, it was a bit of a challenge but I've decided I don't want to wear it here. We don't eat at a pre-set time, we eat when we feel like it. There is nothing we have to do at a certain time, we take things as they come. 
As with the foregoing participant, as well as many others, there is a focus on non-obligation and the relaxing of time constraints. 'Doings' happen at their own tempo, transforming washing dishes into a 'cosy' social moment. As a woman in her mid-twenties, travelling with her boyfriend in a borrowed caravan, observed of caravanning:

I think it's the simplicity, and getting away from the everyday in an easy way, there are no obligations here, you just have your little caravan. And there is no stress and people are so nice. And also just the thing about dishwashing, you hate it when you are doing it at home but now it is cosy, now we go and do the dishes every night and it's so stupid and banal, right? But you just do those little things and relax and don't really do any planning, and that's the diametrical opposition to our daily lives, perhaps that's the attraction.

These banal everyday things are what for most people make up the attraction of caravanning, with the relative absence of stress and timetables transforming chores into social events. Perceptions of free choice turn into enactments of sociality, togetherness and relaxation. As Binnie et al. (2007: 168) argue ' $[t]$ he perforation of the ordinary by the extraordinary can bring forth transformative or even enchanting moments or situations'. The accentuation of these doings perhaps does not mean that they are key events, but represents that other everyday features have taken a backseat, such as time schedules, chores and stress. The down-play of these elements enable experiences of freedom in the simple and mundane, wherein lies immanent extraordinary experiences. These everyday practices like washing dishes, cooking, reading books and walking around the site are not only just parts of the experience, but become ways through which experiences of freedom unfold. This mundane realm offers possibilities for familiarity and security, providing a necessary degree of predictability and comfort. Furthermore, as we discuss in the following section, these tactics of nesting and homing counter masculine representations of freedom.

\section{De-gendering Freedom}

The genderedness of freedom lies in a historical accentuation of maleness in overcoming extreme obstacles and escaping the domestic realms of the female in order to be 'free'. In this study expressions of freedom resisted this gendered dimension. Performances of freedom were instead more grounded and banal. A majority of participants agreed on the crucial importance of the freedom of 
being able to do what one wanted to do when caravanning. A woman in her late twenties travelling with her two female friends accentuated the importance of 'no planning':

We have nothing planned from home. We get up and then we decide what we want to do today... We get up when we want, go to the pool when we want and eat when we want.

It was furthermore underlined by participants that the dwelling unit allowed travelling to many different caravan sites during a holiday. Participants performed freedom in doing what they wanted when they wanted, stressing freedom of choice. This is despite objective constraints the caravan sites may have imposed on choice of activity or style of holiday. Participants experienced freedom from a feeling of being mobile, yet paradoxically engaged most of the time in somewhat immobile doings. People would typically stay at one site for the duration of their holiday. Meals were mostly at normal mealtimes and regular bedtimes were maintained.

Freedom in these findings is thus not represented through the male adventuring explorer. Freedom of mobility is appreciated through perceived choice, and experienced through quite immobile enactments of rest or standstill, which take place largely in and around the domestic realm of the dwelling unit. As emphasized by Neulinger (1981: 16): "[1]eisure, then, has one and only one essential criterion, and that is the condition of perceived freedom. By this we mean a state in which the person feels that what he/she is doing is done by choice and because one wants to do it."

Performativities of freedom through relative immobility, enacted through domestic activities of nesting and dwelling, were not the only practices that countered dominant gendered representations of freedom. Ways in which the body was dressed and adorned were also important, as a woman in her early fifties travelling with her husband, two children and her neighbours from home illustrates:

Nobody expects you to walk around wearing mascara if you don't want to, you can be ugly (laughs), ugly and sweaty, and nobody cares 'cause that's how we all look.

As she asserts, a part of the experience of freedom in caravanning is being able to look how you want. She justifies her individual choice of appearance by referring to it being a collective choice. This was also expressed by a couple in their sixties:

Man: Everyone is equal here.

Woman: that gives a sense of freedom. 
Man: you don't have to wear a tie, you can walk around in a pair of sweats, even if they are completely washed out.

This echoes other interviewees who perceived freedom through 'dressing down' at the caravan site. Freedom was consequently not represented through the rugged, lone male overcoming obstacles, but rather women and men in relaxed wear in everyday domestic spaces. This is not to suggest one can dress/undress how one pleases; through the observations it seemed there exists dressing codes at a caravan site just as everywhere else. When staying at the sites the lead researcher herself quickly adapted to this 'dressing-down' code to fit in, finding it a welcoming opportunity to feel released from everyday 'dressing-up' codes. Andrewes (2005: 34) suggests that dress as a cultural tool, 'prompts the body to behave in a particular way'. In this case it seems dressing-down, and freeing the gendered body of the demands of wearing a tie or wearing mascara, represents performances of freedom. At these caravan sites, the typical distinctions between public and private, home and away, feminized and male domains are thus blurred.

\section{Conclusion}

In this paper we challenged existing dominant discourses that exoticise, masculinise and individualise the subject of freedom. Freedom is too often portrayed through extraordinary acts of adventuring to remote locations while the ordinary and the everyday remain under-researched. This paper has shown how experiences of freedom can occur in close proximity to home and through engaging in ordinary doings. This does not mean that caravanning consists entirely of mundane practices, but that this mundanity can transform into perceived extraordinary experiences. The activities at a caravan site thus consist of 'extraordinary ordinariness' (Haldrup and Larsen, 2003). As Edensor argues (2007: 200) argues: 'although suffused with notions of escape from normativity, tourists carry quotidian habits and responses with them along with their luggage.' This is true for most holidays, however, in this case of caravanning, it seems these quotidian habits and mundane doings are not accidentally and unconsciously carried along on holiday, but are something people purposely seek out, year after year.

Exploring freedom in mundane spaces has also allowed us to view the intersections of gender and freedom from a different perspective. Caravan sites reflect a simultaneous tension of flow and fixity, in which freedom is experienced through perceptions of mobility taking place through relative stillness. The sedentary and the nomadic merge in a domestic realm, which has traditionally been 
portrayed as feminine space. Freedom here is experienced through nesting and dwelling, and through different social expectations surrounding dress and adornment, which challenge gendered representations of freedom associated with maleness, adventure and distance. The paradox of freedom and mobility being balanced out by immobility and routine that emerged in this study deserves further research in other contexts such as second home and time-share visits, visiting friends and relatives in familiar places, or repeat visits to ancestral homes. Such future research can further unpack how travel can be a complex interplay of movement and stasis and of novelty and routine, and the nuances of these relations across different scenarios and settings.

Finally, individualised ideologies of freedom have been historically linked with the autonomy of automobility and the lone subject. Countering this representation, caravanning is enabled by a vehicle, but it stands mostly immobile, wherein mobility is largely perceived through freedom of choice, rather than actual mobility. The car here is paradoxically used to temporarily relocate to a place where one can experience freedom through the closeness of other people and experience a temporary community of safety and trust: freedom is experienced through togetherness.

This paper has shed light on an under-researched area of tourism, that is, domestic caravanning. It has revealed how experiences and performativities of freedom can unfold in mundane, social settings, which reconfigure gendered representations. A limitation in this study, however, is that it has only given voice to a cross-section of heterosexual, Western women and men, undertaking one type of holiday. Freedom is undoubtedly experienced across a range of further practices and lifeworlds that are not necessarily widely perceived as exotic, daring or adventurous. It is to these further underresearched everyday contexts where tourism and the mundane intersect, and to the diversity of experience within them, to which the attention of tourism studies should now also turn.

\section{References}

Adey, P. (2006). If Mobility is Everything Then it is Nothing: Towards a Relational Politics of (Im)mobilities, Mobilities, 1(1), 75-94.

Alcoff, L. M. (1996). Feminist theory and social science. New knowledges, new epistemologies. In: Duncan, N. (Ed.), Bodyspace. Destabilizing geographies of gender and sexuality (pp. 13-27). London and New York: Routledge. 
Andrewes, J. (2005). Bodywork: Dress as a cultural tool. Dress and Demeanor in the South of Senegal. African Social Studies Series, ISSN 1568-1203; vol. 7. Boston MA: Brill.

Baerenholdt, J. O., Haldrup, M., Larsen, J. \& Urry, J. (2004). Performing Tourist Places. New directions in tourism analysis. Ashgate Publishing Limited.

Beck, U. \& Beck-Gernsheim, E. (2001). Individualization: Institutionalized Individualism and its Social and Political Consequences. London: Sage Publications.

Beck, U. (1992). Risk Society: Towards a New Modernity. London: Sage Publications.

Beedie, P. \& Hudson, S. (2003). Emergence of mountain-based adventure tourism. Annals of Tourism Research, 30(3), 625-643.

Berlin, I. (1969). Four Essays on Liberty. Oxford: Oxford University Press.

Binnie, J., Edensor, T., Holloway, J., Millington, S. \& Young, C. (2007). Editorial. Mundane mobilities, banal travels. Social \& Cultural Geography, 8(2), 165-174.

Blichfeldt, B. S. \& Mikkelsen M. (2013). Vacability and sociability as touristic attraction. Tourist Studies, 13, 235.

Boniface, M. (2006). The meaning of adventurous activities for 'women in the outdoors'. Journal of Adventure Education and Outdoor Learning, 6(1), 9-24.

Boyatzis, R.E. (1998). Transforming qualitative information: Thematic analysis and code development. London: Sage Publications.

Braun, V., \& Clarke, V. (2006). Using Thematic Analysis in psychology. Qualitative Research in Psychology, 3(2), 77-101.

Buswell, L., Zabriskie, R. B., Lundberg, N. \& Hawkins, A. J. (2012). The Relationship Between Father Involvement in Family Leisure and Family Functioning: The Importance of Daily Family Leisure. Leisure Sciences: An Interdisciplinary Journal, 34(2), 172-190.

Caldicott, R. W. (2011). Supply-side evolution of caravanning in Australia: An historical analysis of caravan manufacturing and caravan parks, Thesis, Southern Cross University, Lismore, NSW. Retrieved at: http://works.bepress.com/rod_caldicott/2/. 
Capdevila, M. I. S. (2003). 'He comes back badder and bigger than ever!' Readapting the masculine and negotiating the feminine in treasure-hunting adventure fiction. Journal of Gender Studies, 12(3), 215-228.

Carr, N. (2006). A comparison of adolescents' and parents' holiday motivations and desires. Tourism and Hospitality Research, 6(2), 129-142.

Caruana, R. \& Crane, A. (2011). Getting away from it all. Exploring Freedom in Tourism. Annals of Tourism Research, 38(4), 1495-1515.

Casinowsky, B. G. (2013). Working Life on the Move, Domestic Life at Standstill? Work-related Travel and Responsibility for Home and Family. Gender, Work and Organization, 20(3), 311-326.

Cohen, E., \& Cohen, S. A. (2015). A mobilities approach to tourism from emerging world regions. Current Issues in Tourism, 18(1), 11-43.

Counts, D. A. \& Counts, D. R. (2004). Over the next hill: An ethnography of RVing seniors in North America (2nd ed.).Peterborough: Broadview Press.

Collins, D. \& Kearns, R. (2010). 'Pulling up the Tent Pegs?' The Significance and Changing Status of Coastal Campgrounds in New Zealand, Tourism Geographies: An International Journal of Tourism Space, Place and Environment, 12(1), 53-76.

Coleman, S. \& Crang, M. (Eds.) (2002). Tourism. Between Place and Performance. Oxford: Berghahn Books.

Conquergood, D. (2002). Performance Studies: Interventions and Radical Research. TDR (1988-), Vol. 46, No. 2, pp. 145-156.

Cresswell, T. (1993). Mobility as resistance: a geographical reading of Kerouac's 'On the Road', Transactions of the Institute of British Geographers, 18(2), 249-262.

Cronin, A. M. (2000). Consumerism and 'compulsory individuality'. Women, will and potential. In: Transformations: Thinking Through Feminism. McNeil, Maureen, Lury, Celia, Ahmed, Sarah (Eds). London: Routledge.

Dann, G. (1999). Writing out the tourist in space and time. Annals of Tourism Research, 26(1), 159187. 
Decrop, A. (1999). Triangulation in qualitative tourism research. Tourism Management, 20(1), 157161.

Denzin, N. K. \& Lincoln, Y. S. (2005). Introduction: The discipline and practice of qualitative research. In: Denzin, N.K., Lincoln, Y.S. (Eds.), The Sage Handbook of Qualitative Research. Sage Publications: Thousand Oaks, California.

Dilley, R. E., \& Scraton, S. J. (2010). Women, climbing and serious leisure. Leisure Studies, 29(2), $125-141$.

Doughty, K., \& Murray, L. (2014). Discourses of Mobility: Institutions, Everyday Lives and Embodiment, Mobilities, doi: 10.1080/17450101.2014.941257

Edensor, T. (2007). Mundane mobilities, performances and spaces of tourism, Social \& Cultural Geography, 8:2, 199-215.

Edensor, T. \& Holloway, J. (2008). Rhythmanalysing the coach tour: The Ring of Kerry, Ireland. Transactions of the Institute of British Geographers, 33, 483-501.

Edensor, T. (2000). Staging tourism: Tourists as performers. Annals of Tourism Research. 27(2), $322-344$.

Elsrud, T. (2001). Risk creation in traveling: Backpacker Adventure Narration. Annals of Tourism Research, 28(3), 597-617.

Enevold, J. (2000). Men and women on the move: Dramas of the road. European Journal of Cultural Studies, 3, 403-420.

Featherstone, M. (1992). The Heroic Life and Everyday Life. Theory, Culture and Society. 9, 159182.

Flamm, M., \& Kaufmann, V. (2006). Operationalising the Concept of Motility: A Qualitative Study, Mobilities, 1(2), 167-189.

Franklin, A., \& Crang, M. (2001). The trouble with tourism and travel theory? Tourist Studies, 1(1), 5-22.

Franklin, A. (2003). Tourism: An introduction. London: Sage. 
Freudendal-Pedersen, M. (2009). Mobility in Daily Life. Between Freedom and Unfreedom. Surrey: Ashgate.

Freund, P. \& George, M. (2007). Hyperautomobility, the Social Organization of Space, and Health. Mobilities: 2, 37-49.

Ganser, A. (2009). Spatial Practices: An Interdisciplinary Series in Cultural History, Geography and Literature. Roads of Her Own: Gendered Space and Mobility in American Women's Road Narratives, vol. 8, 1970-2000.

Garst, B., A., Williams, D. R. \& Roggenbuck, J. W. (2009). Exploring Early Twenty-First Century Developed Forest Camping Experiences and Meanings, Leisure Sciences: An Interdisciplinary Journal, 32:1, 90-107.

Ghimire, K. B. (Ed.). (2001). The Native Tourist: Mass Tourism within Developing Countries. London: Earthscan.

Habermas, J. (1992). Further Reflections on the Public Sphere. In Habermas and the Public Sphere. C. Calhoun (Ed.). Pp. 421-461. Cambridge, MA: MIT Press.

Hagman, O. (2003). Mobilizing meanings of mobility: Car users' constructions of the goods and bads of car use, Transportation Research D, 8(1), 1-9.

Hall, C. M., \& Müller, D. K. (Eds.). (2004). Tourism, mobility and second homes: Between Elite landscape and common ground. Clevedon: Channel View.

Haldrup, M. \& Larsen, J. (2003). The family gaze. Tourist studies. 3(1) 23-45.

Haldrup, M. (2004). Laid-Back Mobilities: Second-Home Holidays in Time and Space, Tourism Geographies: An International Journal of Tourism Space, Place and Environment, 6:4, 434-454.

Hannam, K., Butler, G. \& Paris, C. M. (2014). Developments and key issues in tourism mobilities. Annals of Tourism Research 44, 171-185.

Hanson, S. (2010). Gender and mobility: new approaches for informing sustainability, Gender, Place \& Culture: A Journal of Feminist Geography, 17:1, 5-23. . 
Hardy, A., Gretzel, U., \& Hanson, D. (2013). Travelling neo-tribes: Conceptualising recreational vehicle users, Journal of Tourism and Cultural Change, 11:1-2, 48-60.

Harrison, P. (2000). Making sense: embodiment and the sensibilities of the everyday. Environment and Planning D: Society and Space, 18, $497-517$.

Hirschmann, N. J. P. (2002). Subject of Liberty: Toward a Feminist Theory of Freedom. Princeton University Press.

Holloway, D. J. \& Holloway, D. A. (2011). Everyday Life in the "Tourist Zone". M/C Journal, 14(5). Retrieved: http://journal.mediaculture.org.au/index.php/mcjournal/article/viewArticle/412

Ingold, T. (1993). The Temporality of the Landscape. World Archaeology, 25(2), Conceptions of Time and Ancient Society, 152-174.

Iso-Ahola, S. E. (1982). Toward a social psychological theory of tourism motivation: a rejoinder. Annals of Tourism Research, 9(2), 256-262.

Jaakson, R. (1986). Second-home domestic tourism. Annals of Tourism Research, 13. 357-391.

Jacobsen, J. K. S. (2004). Roaming Romantics: Solitude-seeking and Self-centredness in Scenic Sightseeing, Scandinavian Journal of Hospitality and Tourism, 4:1, 5-23.

Jensen, M. (1999). Passion and heart in transport - A sociological analysis on transport behaviour. Transport Policy, 6(1), 19-33.

Jensen, O. B. (2006). 'Facework', Flow and the City: Simmel, Goffman, and Mobility in the Contemporary City, Mobilities, 1:2, 143-165.

Jensen, O. B. (2009). Flows of Meaning, Cultures of Movements - Urban Mobility as Meaningful Everyday Life Practice, Mobilities, 4:1, 139-158.

Jokinen, E. \& Veijola, S. (1997). The disoriented tourist: The figuration of the tourist in contemporary cultural critique. In: Touring Cultures. Transformations of travel and theory. C. Rojek \& J. Urry (Eds). London : Routledge. 
Jordan, F. \& Gibson, H. (2004). Let your data do the talking. Researching the solo travel experience of British and American women, in J. Phillimore and L. Goodson (Eds), Qualitative Research in Tourism. Ontologies, Epistemologies and Methodologies, London: Routledge, pp. 215-35.

Kane, M. J. \& Tucker, H. (2004). Adventure tourism: The freedom to play with reality. Tourist Studies 4, 217-234.

Kane, M. J. (2013). New Zealand's transformed adventure: From hero myth to accessible tourism experience. Leisure Studies, 32(2), 133-151.

Kerouac, J. On The Road. 1957. Viking Press: New York.

Kidder, J. L. (2013). Parkour: Adventure, Risk, and Safety in the Urban Environment. Qualitative Sociology, 36, 231-250.

Klooster, E., Wijk, J., Go, F. \& Rekom, J. (2008). Educational travel. The Overseas Internship. Annals of Tourism Research, 35(3), 690-711.

Krakauer, J. (1996). Into the Wild. Anchor Books, a division of Random House, Inc. New York.

Kyle, G. T., Absher, J. D., Hammitt, W. E. \& Cavin, J. (2006). An Examination of the MotivationInvolvement Relationship, Leisure Sciences: An Interdisciplinary Journal, 28:5, 467-485.

Larsen, J. (2008). De-exoticizing Tourist Travel: Everyday Life and Sociality on the Move. Leisure Studies, 27 (1), 21-34.

Larsen, J. R. K. (2012). Family Holiday Homescapes. Place, individual and social perspectives on the intra-family experience dynamics at the holiday home destination. $\mathrm{PhD}$ Dissertation, Department of Culture and Global Studies, SPIRIT, Aalborg University.

Larsen, J., Urry, J. \& Axhausen, K. W. (2007). Networks and tourism: Mobile Social Life. Annals of Tourism Research, Vol. 34, No. 1, 244-262.

Little, D. E. (2002). Women and adventure recreation: Reconstructing Leisure Constraints and Adventure Experiences to Negotiate Continuing Participation. Journal of Leisure Research. 34(2), 157-177.

Löfgren, O. (1999). On Holiday: A History of Vacationing. University of California Press. 
Mahadevan, R. (2013). Understanding Senior Self-Drive Tourism in Australia Using a Contingency Behavior Model. Journal of Travel Research, 53(2), 252-259.

Manderscheid, K. (2014). Criticising the Solitary Mobile Subject: Researching Relational Mobilities and Reflecting on Mobile Methods, Mobilities, 9:2, 188-219.

Massey, D. (1994). Space, Place and Gender. Minneapolis: University of Minnesota Press.

McDowell, L. (1993). Space, place and gender relations: Part I. Feminist empiricism and the geography of social relations. Progress in Human Geography 17: 157.

McNiel, J. N., Harris, D. A. \& Fondren, K. M. (2012). Women and the Wild: Gender Socialization in Wilderness Recreation Advertising. Gender Issues 29:39-55.

Mehmetoglu, M., Graham, M. S. Dann \& Larsen, S. (2001). Solitary Travellers in the Norwegian Lofoten Islands: Why Do People Travel On Their Own? Scandinavian Journal of Hospitality and Tourism, 1(1), 19-37.

Meunier, F. L. D. (2013). From bricolage to thickness: Making the most of the messiness of research narratives. Qualitative Research in Organizations and Management: An International Journal, 8(1), $85-100$.

Mings, R. C. (1997). Tracking 'snowbirds' in Australia: Winter Sun Seekers in Far North Queensland. Australian Geographical Studies, 35: 168-82.

Mings, R., \& McHugh, K. (1995). Wintering in American Sunbelt: Linking place and behaviour. The Journal of Tourism Studies, 6(2), 56-61.

Morley, D. (2000). Home Territories: Media, Mobility and Identity. London and New York: Routledge.

Neulinger, J. (1981). The psychology of leisure (2nd Ed.). Charles C. Thomas.

Obrador, P. P. (2003). Being-on-Holiday: Tourist Dwelling, Bodies and Place. Tourist Studies, 3(1), 47-66. 
Obrador P. P., Crang, M., \& Travlou, P. (2009). Taking mediterranean tourists seriously. In P. Obrador Pons, M. Crang, \& P. Travlou (Eds.), Cultures of mass tourism: Doing the mediterranean in the age of banal mobilities (pp. 1-21). Farnham: Ashgate.

Obrador, P. P. (2012). The Place of the Family in Tourism Research: Domesticity and Thick Sociality by the Pool. Annals of Tourism Research 39, 401-420.

Ong, C. and du Cros, H. (2012). The Post-Mao gazes. Chinese Backpackers in Macau. Annals of Tourism Research, 39(2), 735-754.

Onyx, J. \& Leonard, R. (2005). Australian grey nomads and American snowbirds: Similarities and differences. Journal of Tourism Studies, 16(1), 61-68.

O’Reilly, K. (2005). Ethnographic Methods. London: Routledge.

Parmett, H. M. (2015). "Shredding” the Love: A Feminist Political Economy Critique of Gendered Lifestyle Branding. Journal of Sport and Social Issues, 39(3), 202- 224.

Priya U. T. \& Cresswell, T. (2008). Gendered Mobilities. Abingdon, Oxon, GBR: Ashgate Publishing Group.

Rojek, C. (1995). Decentring Leisure: Rethinking Leisure Theory. London: Sage.

Rose, G. (1993). Feminism and Geography: The Limits of Geographical Knowledge. Cambridge: Polity Press.

Sager, T. (2006). Freedom as Mobility: Implications of the Distinction between Actual and Potential Travelling. Mobilities, 1(3), 465-488.

Savage, M. (2000). Class Analysis and Social Transformation. Milton Keynes, Open University Press.

Schänzel, H. A. (2010). Whole-family research: Towards a methodology in tourism for encompassing generation, gender, and group dynamic perspectives. Tourism Analysis, 15(5),

555-569. 
Schänzel, H. A. \& Smith, K. A. (2011). The absence of fatherhood: Achieving true gender scholarship in family tourism research, Annals of Leisure Research, 14(2-3), 143-154.

Schwandt, T. (1998). Constructivist, interpretivist approaches to human enquiry. In N. K. Denzin and Y. S. Lincoln (Eds.) Handbook of Qualitative Research. Thousand Oaks, CA: Sage.

Seigworth, G. \& Gardiner, M. (2004). Rethinking everyday life: And then nothing turns itself inside out, Cultural Studies, 18:2-3, 139-159.

Sheller, M. \& Urry, J. (2000). The City and the Car. International Journal of Urban and Regional Research, 24(4), 737-757.

Sheller, M. (2008). Mobility, Freedom and Public Space. In Bergmann, Sigurd and Tore Sager (Eds.). The Ethics of Mobilities. Rethinking Place, Exclusion, Freedom and Environment. Aldershot: Ashgate.

Sheller, M. (2014). The new mobilities paradigm for a live sociology. Current Sociology 62, 789811.

Shields, R. (1991). Places on the Margin: Alternative Geographies of Modernity. New York: Routledge.

Skeggs, B. (2004). Class, Self, Culture. London: Routledge.

Small, J. (2008). The absence of childhood in tourism studies. Annals of Tourism Research, 35(3), $772-789$.

Sparke, M. (1996). Displacing the field in fieldwork. Masculinity, metaphor and space. In: Bodyspace. Destabilizing geographies of gender and sexuality. N. Duncan (Ed). London and New York: Routledge.

Sutherland, T. (2014). Intensive mobilities: Figurations of the nomad in contemporary theory. Environment and Planning D: Society and Space. 32, 935 - 950. 
Tazim, J., \& Robinson, M. (Eds.). (2009). The SAGE handbook of tourism studies. London: Sage Publications.

Thurmond, V. A. (2001). The Point of Triangulation. Journal of Nursing Scholarship. 33(3), 253258.

Triantafillidou, A., \& Siomkos, G. (2013). Summer camping: An extraordinary, nostalgic, and interpersonal experience. Journal of Vacation Marketing, 19(3), 197-208.

Urry, J. \& Larsen, J. (2012). The Tourist Gaze, 3.0. London: Sage Publications.

Vannini, P. (2011). Constellations of ferry (im)mobility: islandness as the performance and politics of insulation and isolation. Cultural Geographies, 18, 249-271.

Vannini, P. (Ed.). (2009). The Cultures of Alternative Mobilities. Routes Less Travelled, Surrey: Ashgate.

Veijola, S. \& Falin, P. (2014). Mobile neighbouring, Mobilities, 1-18.

Viallon, P. (2012). Retired Snowbirds. Annals of Tourism Research, 39(4), 2073-2091.

Wearing, B. M. (1998). Leisure and Feminist Theory. London: Sage Publications.

White, N. R. \& White, P. B. (2004). Travel as transition. Identity and Place. Annals of Tourism Research, 31(1), 200-218.

Williams, D. R. \& Kaltenborn, B. P. (1999). Leisure places and modernity: The use and meaning of recreational cottages in Norway and the USA. In: D. Crouch (Ed). Leisure/tourism Geographies. Practices and Geographical Knowledge. Pp. 214-230. London: Routledge

Yarnal, C. M. \& Kerstetter, D. (2005). Casting Off: An Exploration of Cruise Ship Space, Group Tour Behavior, and Social Interaction. Journal of Travel Research 43: 368. 